REVIEW

\title{
Impact of heart failure on quality of sleep
}

A Rao, D Gray

Postgrad Med J 2005;81:99-102. doi: 10.1136/pgmj.2003.013300

Chronic heart failure is an important health problem associated with a high mortality and morbidity.

Appropriate treatment reduces mortality and leads to improved exercise tolerance but many patients report poor quality of sleep. Sleep studies of patients with heart failure suggest that sleep disordered breathing is experienced in $50 \%$ of patients and is a powerful predictor of poor prognosis. Sleep disordered breathing broadly comprises obstructive sleep apnoea, when upper airway instability causes mechanical obstruction to breathing; and central sleep apnoea, characterised by an absence of ventilatory effort. Sleep disordered breathing occurring in patients with heart failure is in most part attributable to central sleep apnoea and reflects uncompensated instability of the ventilatory feedback mechanism.

See end of article for authors' affiliations .....................

Correspondence to: Dr A Rao, Department of Cardiology, Queens Medical Centre Nottingham NG'7 2UH, UK; archana.rao@aht. nwest.nhs.uk

Submitted 4 August 2003 Accepted

3 September 2003
C hronic heart failure is an important health problem. Its crude overall prevalence is $0.3 \%-2 \%{ }^{1}$ but in the over $65 \mathrm{~s}$ it increases considerably to $3 \%-13 \% .^{2}$ The associated high mortality and morbidity ${ }^{3}$ creates a considerable socioeconomic burden.

Clinical trials have established that pharmacological interventions can reduce symptoms, improve prognosis, and improve quality of life. ${ }^{45}$

Prognosis has been shown to be dependent upon a range of factors including haemodynamic variables such as cardiac output and pulmonary vascular resistance, ${ }^{6}$ neurohumoral activity, $^{78}$ and electrophysiological parameters such as spontaneous ventricular tachycardia.

Drug treatment often leads to improved exercise tolerance and reduction in fatigue and breathlessness but many patients report poor quality of sleep. Sleep studies of patients with heart failure showed that changes in either respiratory periodicity or frequency, or both, were common, being observed in about one in two patients with impairment in left ventricular function. ${ }^{90}$ Sleep disordered breathing may be reported by an observant spouse, who may be woken by a partner's reduced tidal volume or recurrent episodes of apnoea. ${ }^{9}$ Such abnormal breathing patterns are particularly powerful predictors of poor prognosis. ${ }^{11}{ }^{12}$

\section{PATHOPHYSIOLOGY OF HEART FAILURE AND ITS RELATION WITH SLEEP}

Heart failure is characterised by a decrease in cardiac output attributable to impaired cardiac function; this results in symptoms of exertional and paroxysmal nocturnal dyspnoea, fatigue, orthopnoea, and peripheral oedema.
Blood flow to any region of the body depends on perfusion pressure and resistance to flow, which is controlled by sympathetic nervous system. ${ }^{13}$ Short term regulation of flow is controlled by arterial baroreceptor and chemoreceptor reflexes while long term regulation depends on an interaction between various hormones and the sympathetic system.

Baroreceptors are located in the walls of the carotid sinus and aortic arch and are the terminals of afferent fibres that run in the glossopharyngeal and vagal nerves. These respond to vessel wall distension and signal changes in arterial pressure over a wide range, from about $50 \mathrm{~mm} \mathrm{Hg}$ to $150 \mathrm{~mm} \mathrm{Hg}{ }^{14}{ }^{15}$

Highly specialised chemoreceptors located in the carotid and aortic bodies are stimulated primarily by a decrease in the partial pressure of oxygen in arterial blood. The afferent arm of the reflex runs in the glossopharyngeal and vagus nerves and evokes both an increase in ventilation and sympathetically mediated vasoconstriction in various vascular beds other than the brain and the heart.

Both baroreceptor and chemoreceptor primary afferent fibres terminate in the nucleus tractus solitarius in the brain stem.

Neurally mediated increases in heart and ventilatory rate at the onset of exercise also occur as a consequence of a central command initiated from the cortex.

In long term regulation, a key element is a change in salt retention resulting in a reciprocal change in the level of circulating angiotensin 2, which, if sustained will result in a sustained change in sympathetic activity. This mechanism could be an important factor contributing to the increase in sympathetic nerve activity in conditions such as heart failure where the reninangiotensin system is activated. Increased efferent sympathetic activity may have several adverse effects, ${ }^{16}$ including de-sensitisation and down regulation of cardiac baroreceptors. ${ }^{17}$

\section{CONTROL OF BREATHING}

Ventilatory control maintains the partial pressure of arterial oxygen $\left(\mathrm{PaO}_{2}\right)$ and carbon dioxide $\left(\mathrm{PaCO}_{2}\right)$ within a narrow range, despite fluctuations in oxygen consumption, carbon dioxide production, and changes in basal metabolic rate. Such exquisite control relies on three components-sensors, a central controller, and effectors (fig 1). ${ }^{18}$

Abbreviations: OSA, obstructive sleep apnoea; CSA, central sleep apnoea; REM, rapid eye movement; NREM, non-rapid eye movement; PSG, polysomnography; CPAP, continuous positive airway pressure 


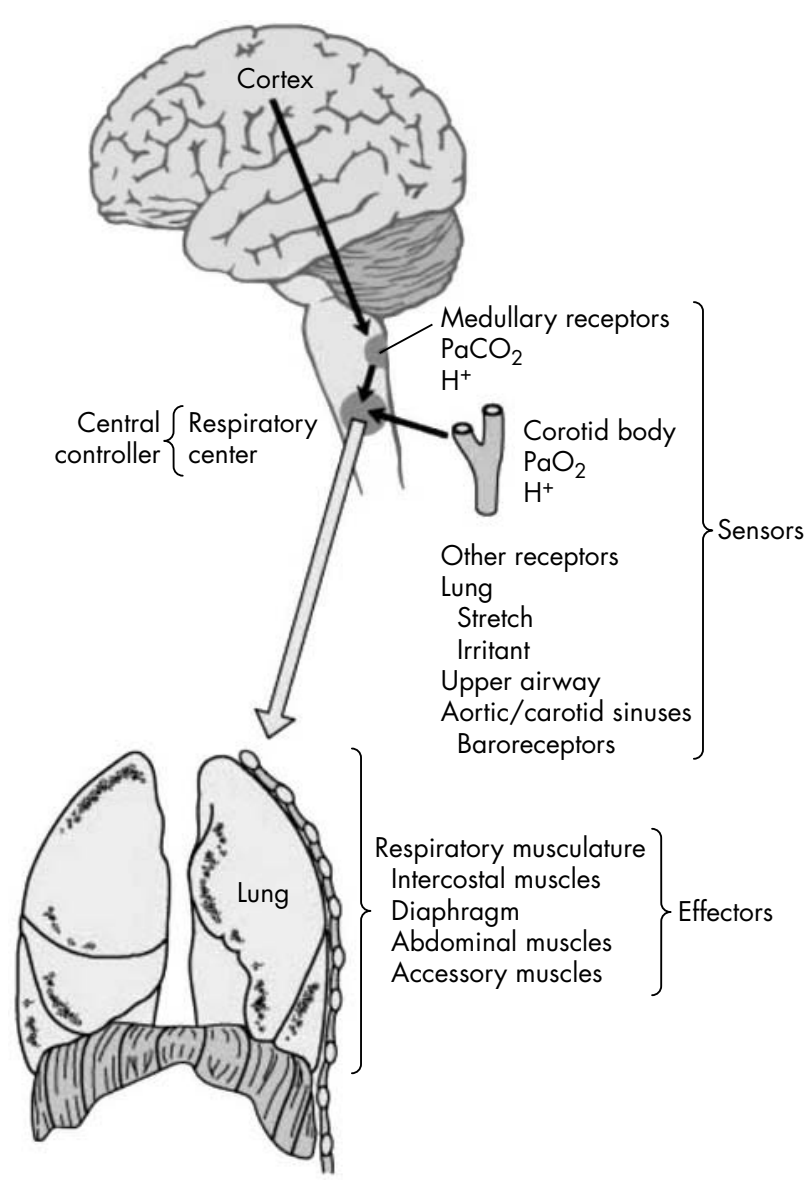

Figure 1 Control of respiration. Reprinted with permission from Waravdekar and Zwillich. ${ }^{18}$

The primary sensors comprise carotid body chemoreceptors that sense $\mathrm{PaO}_{2}$ and hydrogen ion concentration and medullary based chemoreceptors that sense $\mathrm{PaCO}_{2}$ and hydrogen ions. The central controller, the respiratory centre located in the brain stem, sends efferent impulses to effectors, the respiratory musculature of the diaphragm, intercostals, and abdominal muscles.

Normal respiration maintains blood gas and acid-base homoeostasis within strict levels with minimal expenditure of mechanical energy. Breathing is under the control of a negative feedback system. Inputs from higher cortical centres are superimposed on this. In healthy wakeful subjects at rest, a neural feedback loop modifies the respiratory generator to produce a rhythmic ventilatory pattern termed eupnoea. Peripheral arterial chemoreceptors are sensitive to changes in arterial oxygen, carbon dioxide, and hydrogen ion concentrations, while a central chemoreceptor on the ventral surface of the medulla oblongata, in direct contact with cerebrospinal fluid, senses changes in hydrogen ion and carbon dioxide concentrations, both of which are in a buffered equilibrium with the serum.

Hypercapnia, hypoxaemia, and acidaemia stimulate ventilation in humans.

- Ventilation increases in a linear fashion with increasing carbon dioxide concentration. The apnoeic threshold is the value of $\mathrm{PaCO}_{2}$ below which ventilation will cease at a given $\mathrm{PaO}_{2}$.

- Hypoxaemia has a non-linear relation because of the sigmoid shape of the oxy-haemoglobin dissociation curve, which will permit oxygen saturation to remain well in excess of $90 \%$ until $\mathrm{PaO}_{2}$ decreases below this.

- Acidification of the serum brings about an increase in ventilation, mediated acutely via peripheral arterial chemoreceptors.

\section{WHAT HAPPENS IN SLEEP?}

"Normal" sleep comprises two phases, non-rapid eye movement (NREM) and rapid eye movement (REM) sleep. Several cycles of NREM and REM occur, each cycle lasting about 90 minutes $^{19}$ and containing a greater proportion of REM sleep than that preceding it.

During REM sleep, the rate and variability of breathing is increased and most or all skeletal muscle tone is suppressed $^{20}$ because of hyper-polarisation of motor neurons ${ }^{21}$; this prevents muscular contraction, even though brain stem motor systems are intensely active. Arousal to respiratory stimuli, such as hypercapnia or the less potent hypoxia, is delayed in REM sleep. During non-REM sleep, however, breathing patterns are extremely regular and slow, with in particular prolonged inspiratory times. This has profound implications for clinical aspects of sleep, including sleep disordered breathing.

Periods of ventilatory instability are common during the onset of sleep even in normal subjects because the control of breathing becomes critically dependent on the chemical/ metabolic control system, the result of the abolition of the waking neural drive to breathing and behavioural control systems during NREM sleep. As the subject flips from sleep to wakefulness, a ventilation surge occurs that is large enough to drive the $\mathrm{PaCO}_{2}$ below the apnoeic threshold. ${ }^{22}$ Any disease process that exaggerates these parameters will sustain periodic breathing during sleep.

\section{WHAT IS ABNORMAL?}

Sleep disordered breathing broadly comprises obstructive sleep apnoea (OSA), when upper airway instability causes mechanical obstruction to breathing; and central sleep apnoea (CSA), characterised by an absence of ventilatory effort.

In OSA, apnoeic episodes are associated with continued respiratory effort, resulting in hypoxaemia and hypercapnia. Arousal from sleep is purposeful in so much as it leads to removal of mechanical obstruction to breathing and is disruptive to sleep architecture.

Two forms of CSA are recognised. ${ }^{23}$ In the hypercapnic form, respiratory drive is chronically depressed with hypercapnia during wakefulness and sleep. ${ }^{24}$ In the more prevalent hypocapnic form, nocturnal breathing is periodic, characterised by a regular, crescendo-decrescendo oscillation of tidal volume probably caused by dysfunction of central respiratory control. As central respiratory drive slowly fades, ventilation temporarily ceases, then resumes again; this results in an oscillation between hyperventilation ${ }^{25}$ and central hypopnoea (a 50\% reduction in the sum of thoracoabdominal movements lasting 10 seconds or more followed by a decrease of $>4 \%$ in peripheral oxygen saturation) or central apnoea (a reduction of more than $90 \%$ in thoracoabdominal movement or complete cessation of ventilatory effort).

Intervals of hyperventilation separated by periods of hypopnoea are described as periodic breathing. In heart failure, disturbances in the chemical control mechanisms involved with the maintenance of blood gas and acid-base homoeostasis lead to a characteristic respiratory pattern called Cheyne-Stokes respiration, when both hypopnea and apnoea are present. ${ }^{10}$ 


\section{DIAGNOSING SLEEP DISTURBED BREATHING PATTERNS}

Polysomnography (PSG) is a long established method for diagnosing sleep disordered breathing and the standard Rechtschaffen and Kales (1968) criteria have proved to be a reproducible and robust tool for identification and characterisation of sleep state.

Nocturnal PSG, however, is expensive, unobtainable in a timely fashion for many patients, and labour intensive for both patient and investigator.

The US Department of Health and Human Services reported that there was "no standard for diagnosing sleep disorders" and recommended that PSG "be compared with alternative low technology approaches such as questionnaires, home monitoring...for making the initial diagnosis" ${ }^{26}$

Since then, home based monitoring systems, ranging from simple oximetry ${ }^{27} 28$ to limited channel portable polysomnography and "smart" continuous positive airway pressure (or CPAP) machines ${ }^{29}$ with unattended monitors, an adhesive finger oximeter, and chest belts with mercury switch to indicate body position ${ }^{30}$ have been shown to acceptable, albeit less sensitive, measures of sleep disordered breathing.

\section{LIMITATIONS}

When performing ambulatory sleep monitoring outside the laboratory setting, quality and integrity of data are particularly important. Scoring these "unattended" studies is made more difficult as electrode artefacts arise from oximeter disturbances caused by patient movement and unit malfunction. $^{31}$

\section{PREFERRED MEASUREMENT INDICES}

Sleep disordered breathing, particularly OSA, has traditionally been defined according to the apnoea-hypopnoea index, calculated as the sum of apnoeic and hypopneic episodes per hour of sleep.

There is only one widely used definition of apnoeacessation of airflow for more than 10 seconds-but the definition of hypopnoea varies widely and includes various degrees of reduction in airflow and/or thoraco-abdominal movement with an associated oxygen desaturation. This is particularly relevant when comparing studies from different centres.

\section{PREVALENCE OF SLEEP DISORDERED BREATHING}

Obstructive sleep apnoea occurs in $4 \%$ of men and $2 \%$ of women in the general population, between the ages of 30 to 60 years $^{32}$ but sleep disordered breathing is much more common in patients with heart failure $-40 \%-50 \%$ of those with chronic ${ }^{933}$ and up to $80 \%$ in acute heart failure. ${ }^{34}$

\section{PATHOGENESIS}

Sleep disordered breathing occurring in patients with heart failure is in the most part attributable to central sleep apnoea $^{91235}$ and reflects uncompensated instability of the ventilatory feedback mechanism. ${ }^{23}$ In general, feedback controls de-stabilise if their damping capacity is overridden (see below). This can occur if the information transfer is delayed or controller gain is changed. ${ }^{36}$

\section{INCREASED CONTROLLER GAIN}

Increased sensitivity of the respiratory centre to carbon dioxide leads to an oscillating hypocapnia ${ }^{37}$ induced by hyperventilation during sleep, with ventilation ceasing when $\mathrm{PaCO}_{2}$ decreases below the apnoea threshold. The endogenous catecholamines norepinephrine (noradrenaline) and adrenaline (epinephrine) can change chemoreceptor sensitivity. ${ }^{38}$
Levels of both hormones are raised in patients with heart failure, probably as a compensation for cardiac pump failure. Increased circulating concentrations of these catecholamines might increase the responsiveness of respiratory controller to carbon dioxide, leading to hyperventilation. ${ }^{40}$

\section{UNDER-DAMPING}

The ratio of the volume of stored gas in the body to change in gas tension in the blood is known as the dampening ratio. ${ }^{22}{ }^{36}$ Larger stores of carbon dioxide allow for better buffering and thus stability of arterial blood gas tensions during transient changes in ventilation. In patients with heart failure, the functional residual capacity is reduced because of pulmonary vascular congestion and thus pulmonary gas volume is decreased. As a result, total body stores of carbon dioxide and oxygen are both decreased and the respiratory system becomes much more unstable. ${ }^{42}$

\section{PROLONGED CIRCULATION TIME}

In heart failure, a circulatory time delay can occur between the gas exchange occurring at the alveolar capillary membrane of the lungs and carotid body chemoreceptors. ${ }^{36143}$ This results in delayed feedback to the medulla, causing instability of gas homoeostasis and to periodic respirations.

\section{PROGNOSIS}

There is an increased incidence of hypertension, ${ }^{30}$ arrhythmia, myocardial infarction, ${ }^{44}$ and stroke, ${ }^{45}$ so obstructive sleep apnoea is not a benign condition. ${ }^{46-48}$

The development of sleep disordered breathing occurring in patients with heart failure has serious implications. The prognosis of patients is worse if congestive heart failure is associated with a sleep apnoea syndrome. ${ }^{49}$ The prevalence of cardiac arrhythmias is higher than in patients with the same degree of heart failure who do not experience periodic breathing. ${ }^{12}{ }^{33}$ Patients with periodic breathing are more limited and develop dyspnoea at lower workload. A survey of patients in chronic congestive heart failure with and without Cheyne-Stokes respiration showed that patients with disordered breathing had significantly worse cumulative survival and transplant free rate. ${ }^{11}$

The typical symptoms of sleep disordered breathing include daytime hypersomnolence and fatigue. Repetitive arousals cause sleep fragmentation with a reduction in the amount of slow wave and REM sleep, the most refreshing sleep stages. $^{50}{ }^{51}$ It is also responsible for impaired psychomotor performance in patients with heart failure. ${ }^{52}$

\section{CHANGING THE NATURAL HISTORY}

Improvement of cardiac function can improve Cheyne-Stokes respiration associated with heart failure. ${ }^{42}$ It is important to optimise the medical treatment of the underlying heart disease before considering specific treatment for periodic breathing, ${ }^{53}$ which includes drug treatment, supplemental oxygenation, and ventilation.

Theophylline, ${ }^{54}$ morphine derivatives, and supplementation of inhaled oxygen with $3 \%$ carbon dioxide ${ }^{55}$ have been successfully applied under experimental conditions in small studies. Supplementing oxygen overnight with flow rates of two to three litres per minute can reduce Cheyne-Stokes respiration by half and can improve sleep architecture ${ }^{56}$; exercise performance and cognitive function may improve although daytime symptoms may not. ${ }^{57} 58$ Nocturnal, noninvasive ventilation using continuous positive pressure ventilation (CPAP) for a period of one month can significantly reduce the frequency of apnoeas and hypopneas, increase oxygen saturation and $\mathrm{PCO}_{2}$, and normalise tidal volume during sleep. ${ }^{59}$ 


\section{CONCLUSION}

Sleep disordered breathing occurs commonly in patients with heart failure but is often unrecognised, perhaps because its associated symptoms, fatigue, impaired physical performance, dismal quality of life, and cognitive impairment are attributed to heart failure. Current therapeutic approaches have focused on correction of the abnormal breathing pattern, the most readily available and most successful being CPAP and supplemental oxygen. There are no conclusive studies on long term outcome of any treatment in sleep disordered breathing.

Although pharmacological interventions have improved the outlook for millions of patients with heart failure, the prognosis for those with periodic breathing remains poor.

\section{Authors' affiliations}

A Rao, D Gray, Department of Cardiology, Queens Medical Centre, Nottingham, UK

Funding: none.

Conflicts of interest: none declared.

\section{REFERENCES}

1 Cowie MR, Struthers AD, Wood DA, et al. Value of natriuretic peptides in assessment of patients with possible new heart failure in primary care. Lancet 1997; 350:1349-53.

2 Schocken DD, Arrieta MI, Leaverton PE. Prevalence and mortality rate of congestive heart failure in the United States. J Am Coll Cardiol 1992;20:301-6.

3 Sans S, Kesteloot S, Kromhout D. The burden of cardiovascular diseases mortality in Europe. Task Force of the European Society of Cardiology on Cardiovascular Mortality and Morbidity statistics in Europe. Eur Heart $J$ 1997; 18:1231-48.

4 The CONSENSUS Trial Study Group. Effects of enalapril on mortality in severe congestive heart failure. Results of the cooperative North Scandinavian enalapril survival study (CONSENSUS). N Engl J Med 1987;316:1429-35.

5 CIBIS 2 investigators and committees. A randomised study: the cardiac insufficiency bisoprolol study 2 (CIBIS 2), Lancet 1999;353:9-13.

6 De Hoyos A, Liu PP, Bernard D. Hemodynamic effects of CPAP in humans with normal and impaired left ventricular function. Clin Sci 1995;88:173-8.

7 Francis GS, Benedict C, Johnstone DE, et al. Comparison of neuroendocrine activation in patients with left ventricular dysfunction with and without congestive heart failure. A substudy of the studies of left ventricular dysfunction (SOLVD). Circulation 1990;82:1724-9.

8 Ferrari R, Ceconi C, Curello $S$, et al. The neuroendocrine and sympathetic nervous system in congestive heart failure. Eur Heart J 1998;19(suppl F):F45-51.

9 Javaheri S. Occult sleep-disordered breathing in stable congestive heart failure. Ann Intern Med 1995; 122:478-92.

10 Kohnlein T, Klante T, Elliott MW, et al. [Heart failure and central respiratory dysregulation. Cheyne-Stokes respiration during sleep in advanced left heart failure]. Pneumologie 2001;55:13-20.

11 Hanly P, Kokhar Z. Increased mortality associated with Cheyne -Stokes respiration. Am J Respir Crit Care Med 1996;153:272-6.

12 Lanfranchi PA, Braghiroli A, Bosimini E, et al. Prognostic value of nocturnal Cheyne-Stokes respiration in chronic heart failure. Circulation 1999:99:1435-40.

13 Dampney RA. Central mechanisms underlying short and long term regulation of the cardiovacsular system. Clin Exp Pharmacol Physiol 2002;29:261-8.

14 Prescott E, Hippe M, Schnohr P, et al. Smoking and risk of myocardial infarction in women and men: longitudinal population study. BMJ 1998:316:1043-7.

15 Kirchheim HR. Systemic arterial baro receptor reflexes. Physiol Rev 1976;56:100-76.

16 Leimbach WN, Wallin BG, Victor RG, et al. Direct evidence from intra neural recordings for increased sympathetic oufflow in patients with heart failure. Circulation 1986:73:913-19.

17 Bristow MR, Ginsburg R, Umans V. Beta sub and beta sub 2 adrenergic receptor populations in non failing and failing human ventricular myocardium: coupling of both receptor sub types to muscle contraction and selective beta sub receptor down -regulation in heart failure. Circ Res 1986:59:297-309.

18 Waravdekar NV, Zwillich CW. DISEASEDEX general medicine. In: Gotto A ed. DISEASEDEX general medicine. [Adapted from Zwillich C: The control of breathing in clinical practice, its significance and assessment.] Colorado: Thomson MICROMEDEX, Green wood Village, 1999.

19 Cooper R. Normal sleep. Cambridge: Chapman and Hall Medical, 1994:3-46

20 Jouvet $M$. Recherches sur les structures nerveuses et les mechanismes responsables des differentes phases du sommeil physiologique. Arch ltal Biol 1962; 100:125-206.
21 Chase MH, Morales FR. The atonia and muscle active (REM) sleep. Annu Rev Pscychol 1990;41:557.

22 Chapman KR, Bruce N, Gothe B. Possible mechanisms of periodic breathing during sleep. J App Phyisiol 1988;64:1000-8.

23 Kohnlein T. Central sleep apnoea syndrome in patients with chronic heart disease: a critical review of the current literature. Thorax 2002;57:547-54.

24 Krachman S, Ciner GJ. Hypoventilation syndromes. Clin Chest Med 1998; 19:139-55.

25 ATS. Indications and standards for cardiopulmonary sleep studies. American Review of Respiratory Disease 1989;139:559-68.

26 Agency for Health care Policy and Research Polysomnography and Sleep Disorders Centre. Health Technol Assess Rep 1991 ;number 4.

27 Reference withdrawn.

28 Staniforth AD, Kinnear WJ, Starling R, et al. Nocturnal desaturation in patients with stable heart failure. Heart 1997;79:394-9.

29 Reference withdrawn.

30 Fletcher EC, De Behnke RD, Lovoi MS. Undiagnosed sleep apnoea in patients with essential hypertension. Ann Intern Med 1985;103:190-5.

31 Khoo MCK, Gottschal KA, Pack A. Sleep induced periodic breathing and apnoea: a theoretical stud. J Appl Phyisiol 1991;70:2014-24

32 PM, Young T, Dempsey J. The occurrence of sleep-disordered breathing among middle aged adults. N Engl J Med 1993;328:1230-5.

33 Javaheri S, Parker TJ, Leming JD, et al. Sleep apnoea in 81 ambulatory male patients with stable heart failure. Types and their consequences and presentations. Circulation 1998;97:2154-9.

34 Tremel F, Pepin JL, Veale D, et al. High prevalence and persistence of sleep apnoea in patients referred for acute left ventricular failure and medically treated over 2 months. Eur Heart J 1999;20:1201-9.

35 Findley L, Zwillich CW, Anconi-Israel S. Cheyne Stokes breathing during sleep in patients with left ventricular heart failure. South Med J 1985;78:11-15.

36 Cherniack NS, Longobardo GS. Cheyne-Stokes breathing :an instability in physiologic control. N Engl J Med 1973;288:952-7.

37 Naughton M, Benard D, Tam A, et al. Role of hyperventilation in the pathogenesis of central sleep apneas in patients with congestive heart failure. American Review of Respiratory Disease 1993;148:330-8.

38 Weil JV, Bryne-Quinn E, Sodal IE. Augmentation of chemosensitivity during mild exercise in man. J Appl Phyisiol 1972;33:813-19.

39 Swedberg K, Eneroth P, Kjekshus J. Hormones regulating cardiovascular function in patients with severe congestive heart failure and their relation to mortality. Circulation 1990;82:1730-6.

40 Chua TP, Clarke AL, Amadi AA, et al. Relation between chemo sensitivity and the ventilatory response to exercise in chronic heart failure. J Am Coll Cardiol 1996;27:650-7.

41 Tobin MJ, Snyder P. Cheyne Stokes respiration revisited:controversies and implications. Crit Care Med 1984;12:882-7.

42 Quaranta GE, Dalonzo, Krachman SL. Cheyne-Stokes respiration during sleep in congestive heart failure. Chest 1997; 111:467-73.

43 Lange RL, Hecht HH, Mechanism of Cheyne Stokes respiration. J Clin Invest 1962;41:42-52.

44 Hung MJ, Whitford EG, Parsons RW, et al. Association of sleep apnoea with myocardial infarction in men. Lancet 1990;1990:261-4.

45 Palomaki H, Partinen M, Juvela S. Snoring as a risk factor for sleep-related brain infarction. Stroke 1989;20:1311-15.

46 Koskenvuo M, Kaprio J, Telakiwi T, et al. Snoring as a risk factor for ischaemic heart disease and stroke in men. BMJ 1987;294:16-19.

47 Partinen M, Palomaki H. Snoring and cerebral infarction. Lance 1985;2:1125-6.

48 Hung J, Whitford E, Parsons R. Association of sleep apnoea with myocardial infarction in men. Lancet 1988;336:9-14.

49 Wilcox I, McNamara SG, Wessendorf T, et al. Prognosis and sleep disordered breathing in heart failure. Thorax 1998;53(suppl 3):S33-6.

50 Hanley P, Zuberi Kokhar. Day time sleepiness in patients with congestive heart failure and Cheyne Stokes respiration. Chest 1995;107:952-8.

51 Levine B, Stepanski E, et al. Fragmenting sleep diminishes its recuperative value. Sleep 1987;10:590-9.

52 Staniforth AD, Kinnear WJ, Cowley AJ. Cognitive impairment in heart failure with Cheyne-Stokes respiration. Heart 2000;85:18-22.

53 The task force of the working Group on Heart Failure of the European Society of Cardiology. The treatment of heart failure. Eur Heart J 1997:18:736-53.

54 Javaheri S, Parker TJ, Wexler L. Effect of theophylline on sleep disordered breathing in heart failure. N Engl J Med 1996;335:562-7.

55 Steens RD, Millar TW, Su X. Effect of inhaled 3\% CO2 on Cheyne-Stokes respiration in congestive heart failure. Sleep 1994;17:61-8.

56 Hanly P, Millar TW, Steljes DG. The effect of oxygen on respiration and sleep in patients with congestive heart failure. Ann Intern Med 1989;111:777-82.

57 Andreas S, Clemens C, Sandholzer H. Improvement of exercise capacity with treatment of Cheyne Stokes respiration in patients with congestive heart failure. J Am Coll Cardiol 1996;27:1486-90.

58 Staniforth AD, Kinnear WJ, Starling R, et al. Effect of oxygen on sleep quality, cognitive function and sympathetic activity in patients with chronic heart failure and Cheyne-Stokes respiration. Eur Heart J 1998;19:922-8.

59 Naughton MT, Benard DC, Liu PP, et al. Effects of nasal CPAP on sympathetic activity in patients with heart failure and central sleep apnea. Am J Respir Crit Care Med 1995; 152:473-9. 